\title{
Introduction
}

\section{Intersubjectivity and empathy}

Jensen, Rasmus Thybo; Moran, Dermot

Published in:

Phenomenology and the Cognitive Sciences

DOI:

10.1007/s11097-012-9258-y

Publication date:

2012

Document version

Early version, also known as pre-print

Citation for published version (APA):

Jensen, R. T., \& Moran, D. (2012). Introduction: Intersubjectivity and empathy. Phenomenology and the Cognitive Sciences, 11(2), 125-133. https://doi.org/10.1007/s11097-012-9258-y 


\title{
Introduction: intersubjectivity and empathy
}

\author{
Rasmus Thybo Jensen • Dermot Moran
}

Published online: 24 May 2012

(C) Springer Science+Business Media B.V. 2012

Keywords Intersubjectivity $\cdot$ Empathy $\cdot$ Theory theory $\cdot$ Simulation theory $\cdot$ Direct perception

Empathy may be understood as a particular topic within the larger discussion of the nature of intersubjectivity, i.e. discussions about how we are to understand the basic communicative relations between subjects and the importance of such interpersonal relations for our way of relating to the world as a whole. We routinely say of other persons such things as: 'she is angry'; 'he failed to understand my point', 'we are both looking for the same thing', 'we share a point of view', 'I feel your pain', 'I was upset to see Mary in pain', 'I can differentiate between what he said and what he meant', and so on. (The Cambridge Behaviour Scale gives a good series of questions that highlight various forms of empathic understanding, see Baron-Cohen and Wheelwright 2004). Our ability to apprehend, cognize or co-experience the experiences of other subjects (both human and animal) has an older label in the history of psychology: it was originally called 'sympathy' in the tradition of David Hume (Hume 1978) and Adam Smith (Smith 2002). Thus Hume writes:

No quality of human nature is more remarkable, both in itself and in its consequences, than that propensity we have to sympathize with others, and to receive by communication their inclinations and sentiments, however, different from, or even contrary to our own. (Hume 1978, pp. 316-17)

\footnotetext{
R. T. Jensen $(\bowtie)$

Department of Media, Cognition and Communication, Philosophy Section/Danish National Research Foundation: Center for Subjectivity Research, University of Copenhagen, Njalsgade 140-142, 25.5.23, 2300 Copenhagen S, Denmark e-mail: rasmusthybo@yahoo.dk

D. Moran

School of Philosophy, University College Dublin, Dublin 4, Dublin, Ireland e-mail: dermot.moran@ucd.ie
} 
This phenomenon was later termed Einfühlung by the German philosopherpsychologist Theodor Lipps (Lipps 1905; Moran 2004). Under this term 'Einfühlung', it entered into the phenomenological tradition, originally via the works of Husserl, Scheler, Stein and Schutz, and later it was discussed by amongst others Sartre and Merleau-Ponty. In fact, the term 'empathy' first appeared as a translation of Lipps' notion of Einfühlung, which is also sometimes rendered as 'intropathy'. As Lipps, Scheler, Husserl and others all quickly recognized, empathy does not constitute a single phenomenon but is a rather loose term for a large constellation of interrelated and many-layered experiences and activities, central not only to philosophy and psychology, but also to sociology, moral theory, political science and the whole edifice of the Geisteswissenschaften (see Scheler 1954/1973; Stueber 2006).

At some point in the 1970 s, cognitive scientists and philosophers of mind started using the catchy term 'mind reading' to describe what most humans do most of the time in their perceiving, emotionally apprehending, understanding, interpreting and predicting the intentional activity and behaviour (cognitive and emotive) of other humans and some higher animals. The term was probably first introduced into philosophy by Daniel C. Dennett in his 'Brain Writing and Mind Reading' (originally 1975, reprinted in Dennett 1978). Dennett himself was responding to issues raised in Elizabeth Anscombe's groundbreaking book Intention concerning the special ways we seem to acquire knowledge about our own intentional actions (Anscombe 1957). The notion of mind reading is often defined simply as the capacity to attribute mental states to self or other and so is not reserved for our understanding of other minds (cf. Goldman 2008). In fact, those traditionally interested in understanding the functioning of empathy (including Husserl and Lipps) included a person's attempts to recall in memory or to understand earlier stages of his or her self as phenomena falling under the concept. Generally, 'mindreading' is regarded as a subspecies of what is known in psychology as 'metarepresentation' (see Whiten 1991; Sperber 2000), i.e. the ability to represent the representations of oneself or others (see also Goldman 2009; Goldman and Shanton 2010). However, if we define 'mind reading' as the ability to attribute mental states to oneself and to others, it can be used as a theory-neutral term that stands for a crucial explanandum for research in social cognition that allows for different explanantia. What is not uncontroversial, however, is whether 'mind reading' in this sense is always based on the use of capacities that exceed those already in play in our sensory experiences, such as the ordinary meaning of the word suggests.

Broadly speaking the majority of recent explanatory theories concerning our mind reading capacities can be classified as falling under one of two broad approaches:

- the 'theory theory' approach (attribution of mental states via the application of a naïve theory of psychological states and their implications; involves theory-based inferences);

- the 'simulation theory' approach (attribution of mental states via emulation or replication of states of the other; does not necessarily involve inferences).

As James O'Shea highlights in his contribution to this special issue the American philosopher Wilfrid Sellars (1912-1989) is often said to have been the progenitor of the 'theory theory' approach to social cognition. In the form of an empirical theory about mind reading, however, the theory theory is usually said to have originated in a 1978 paper by Premack and Woodruff, 'Does the chimpanzee have a theory of mind?' 
published in Behavioral and Brain Sciences (Premack and Woodruff 1978). The simulation theory also has forerunners that predate the present day theory of mind debate, in particular Lipps' account of empathy shares central features with modern day simulation theories. In recent analytic philosophy, the simulation approach was first championed by Gordon (1986), Heal (1986, 1994) and Goldman (1992). According to simulation theory, a person understands another by imaginatively presenting herself in or transposing herself into the situation of the other. The suggestion is that this way of assigning mental states to others involves comparatively little computation or inference. Simulation theory is greatly assisted by the intuition that the attribution of mental states to others is not usually experienced as a form of inference (hence the objection to the theory theory), although one can easily see that some situations do require the use of inferences. Such reliance on inference come out clearly in cases where we explicitly raise questions about what $\mathrm{X}$ meant or intended when he or she said or did this or that (questions often at issue in criminal law cases).

As a number of authors have recently argued, the analyses of empathy found in the works of some of the classical phenomenologists (notably Husserl and Scheler) challenge both the theory theory and the simulation theory by considering empathy as an irreducible, perception-based understanding of the other, which depends neither on inferences nor on simulation processes (cf. Gallagher 2005, 2006; Gallagher and Zahavi 2008; Zahavi 2010, 2011, 2012; Zahavi and Overgaard 2012). In the analytical tradition, we also find a long list of prominent figures who have argued for the need to recognize the possibility of a direct perceptual grasp of other people's mental states (Austin 1946; Strawson 1999; Wittgenstein 1980, § 927; McDowell 1998a, 1998b). With the papers in this special issue, we wish to contribute to the emerging debate about the internal relations between these different versions of the direct perception approach, as well as to the ongoing debate about the relation between the direct perception approach as such and the 'theory theory' and 'simulation theory' approaches.

All four papers in this issue present versions of the idea that perception can be a direct source of knowledge about the minds of others. We can call this the 'direct perception' thesis (DP). In its most comprehensive version, DP is both a thesis about the psychological mechanisms involved in the formation of certain judgement about other minds and a thesis about the ultimate source of justification of such judgements. This, the comprehensive version of DP, claims that perception can provide the perceiver with knowledge of other minds without the perceiver relying on any actual theorizing or simulation and without the observational judgement receiving its epistemic status as knowledge because of a potential inferential justification. This - the strongest version of the direct perception thesis-involves a commitment to both the psychological immediacy and the epistemic immediacy of certain pieces of knowledge of other minds. However, the epistemic version of DP need not be combined with the psychological version and the psychological version-regardless of whether it is a thesis concerning personal or sub-personal processes-need not be combined with the epistemic version. Both Rowland Stout and Joel Krueger defend epistemic versions of DP in their respective contributions. Krueger explicitly combines the epistemic thesis with the psychological version both at the personal and at the sub-personal level. James O'Shea, in his paper "The "theory theory" of mind and the aims of Sellars' original Myth of Jones', argues that Wilfrid Sellars' original version of the 'theory theory' can accommodate many, if not all, of the objections 
raised against the 'theory theory' by proponents of the direct perception approach. It can do so because it subscribes to a psychological version of DP at the personal level, while denying that our knowledge of others is epistemically non-inferential. As O'Shea notes, this combination of a personal level psychological immediacy and epistemic indirectness can coherently be combined with both a theory theory account and a simulation account at the sub-personal level. Finally, in their paper 'The extended body: a case study in the neurophenomenology of social interaction', Froese and Fuchs argue for the possibility of accounting for some basic phenomena of social interaction via a dynamical systems theory approach. They argue for the psychological version of DP both at the personal and at the sub-personal level.

In what follows, we provide a brief summary of the four papers and point out certain points of agreement and disagreement as well as questions for future research.

In his paper, Rowland Stout raises the question of how we should think of the relation between other people's behaviour and their emotional states if it is to be so much as possible that we can directly perceive people's emotional states when we perceive their behaviour. Stout does not argue for the thesis that we can in fact directly perceive the emotional states of other people, but rather he takes it for granted that we can, and proceeds to ask how we can make this possibility theoretically intelligible. This does not mean that he denies that there is a substantial philosophical question about the possibility of such a direct perceptual access to other minds. On the contrary, he proceeds by identifying a certain conception of causal relations (the Humean event-causal model) that can make it look like such a direct perception is indeed impossible. On the Humean account, the causal relation is conceived as a relation between events and it is regarded as extrinsic to both the causing event and the caused event. The causal relation itself is not regarded as part of the perceivable world. All we see is a sequence of events or event stages, one following the other, but that one sequence is the cause of another can only be established by going beyond that which is given in perception. This means that the attribution of mental state to others must remain a hypothesis about a hidden cause that gives rise to the independently observable behaviour. One way to hold on to the idea of the direct perception thesis in the face of the Humean analysis would be to dismiss the very idea that we should analyse the relation between mental items and expressive behaviour in terms of causality. This is not Stout's response. Stout takes the idea that for instance, my anger causes my face to contort as just as much a part of our datum as the possibility of direct perception of emotions. With this premise, it is obvious that what we need in order to show that we are not obligated to deny DP is an alternative to the Humean conception of causality. This is exactly what Stout presents in the form of the Aristotelian process-causal model. According to the Aristotelian model, the mental state is to be conceived as a potential, and the expressive behaviour is conceived as the process of realizing the potential rather than as an observable sequence of event stages caused by an inner, unobservable event. Just as we can immediately feel, the strength of a person in her handshake, we can immediately see her anger in her facial expressions, now understood not as a sequence of facial distortions but as the process of actualizing the anger. The process is ongoing here and now in plain sight, whereas the event can really only be referred to after the fact.

The papers of Krueger and of Froese and Fuchs also highlight the idea of the mental as unobservable as an unquestioned assumption common to and motivating 
both the theory theory approach and the simulation theory approach. What is distinctive about Stout's contribution is how he diagnoses this 'unobservability principle' as the upshot of certain basic metaphysical assumptions about the nature of causality and a certain metaphysical prioritizing of events over processes. In addition, Stout brings out how these metaphysical assumptions go hand in hand with a conception of perception as a passive receiving of impressions. Opposing this passive picture of perception, Stout opts for an enactive account. Here, it becomes obvious that Stout's approach is not just diagnostic. He does not just point to the abstract possibility of an alternative conception of causality but further argues that this conception neatly fits a specific theory of perception.

Like Stout, Krueger, in his paper 'Seeing mind in action', asks how we should conceive of expressive behaviour if we are to make sense of the direct perception thesis. Krueger argues that the best way to spell out DP is by exploiting ideas developed within the framework of the extended mind hypothesis. Krueger's main thesis is that we ought to understand the relation between expressive behaviour and expressed mental states as a constitutional relation: the behaviour literally constitutes parts of mental states or processes. Just like Otto's notebook, in Clark and Chalmers (1998) famous example, allegedly forms a constitutive part of cognitive processes, so, Krueger argues, gestures in certain instances form constitutive parts of a thinking process and, similarly, facial expressions can be constitutive parts of an emotional state or process. Krueger's overall argument has two steps. In the first step, he argues that the constitution interpretation of the expressive relation is required in order for us to hold on to the direct perception thesis (DP) in its epistemic version. Krueger's argument here parallels Stout's argument to the effect that only if we adopt an Aristotelian process-causal interpretation of the expressive relation can we make sense of the possibility of direct perceptual access to other minds. This raises interesting questions about the relation between the two authors respective conceptions of the expressive relation between mental phenomena and bodily behaviour. Krueger in his paper explicitly follows Stout, whom he acknowledges, in rejecting the Humean event-causal model and states the constitution thesis via the notion of processes: It is the cognitive or emotional process that is distributed across both intracranial and extracranial behavioural elements and the perceivable parts of the mental phenomena are parts of a dynamic process. However, Krueger also explicitly denies that we can directly perceive dispositions, something Stout, as Krueger notes, argues is vital for a defence DP. Krueger's denial of the possibility of direct perception of dispositions is part of his arguments against Joel Smith's recent defence of the epistemic direct perception thesis.

The second step in Krueger's overall argument differs from the argumentative strategy followed by Stout by explicitly drawing on empirical research. In the first step, Krueger argued that the constitution interpretation of the expressive relation, in contrast to Smith's copresence interpretation (Smith 2010), can make sense of the epistemic version of DP. Just as Stout's arguments for the need to adopt the Aristotelian model rest upon the assumption that this model is the only alternative to the Humean model that will allow us to make sense of the direct perception thesis, so the first step of Krueger's argument rely on the lack of alternatives to the two accounts considered, namely, the constitution and the copresence interpretation of DP. The second step of Krueger's argument serves the purpose of providing independent empirical support for the idea that the mind literally extends into perceivable gestures 
and expressions, and thereby support for the constitution interpretation. Krueger appeals to a number of studies of how gestures can enhance cognitive abilities and of how lack of possibility of bodily expression in for instance individuals with Moebius syndrome can significantly decrease the intensity of emotions. He further argues that the extended cognitive and emotional processes play a crucial role in social interaction and that they do so by being at least in part immediately perceivable. Krueger stresses that his account does not reduce mental phenomena to behaviour. It is only parts of the mental state or process which are visible, leaving both aspects of the states what-it-is-likeness and its physical vehicle hidden. At this point, we seem to return to the question of how exactly to distinguish this distinction between observable and unobservable parts from the copresence model which distinguishes between literally seen aspects of the mental and the co-presented aspects, a question that undoubtedly will be the focus of future discussion.

James O'Shea's paper, 'The "theory theory" of mind and the aims of Sellars' original Myth of Jones', presents a detailed explication of Wilfrid Sellars' account of the nature of our knowledge of other minds. Sellars is often recognized (by Dennett amongst others (Dennett 1987, pp. 341)) as one of the first to propose an analogue between the way we ascribe mental states to ourselves and others and the way science posits theoretical entities in order to explain the observable behaviour of macroscopic objects. O'Shea argues that Sellars draws some useful distinctions which tend to be overlooked in the present day discussion, giving rise to unnecessary confusions. As O'Shea observes, the direct perception approach to social cognition is often motivated by phenomenological and epistemological consideration. O'Shea argues that Sellars' version of the theory theory can accommodate these motivations. It is a crucial point for O'Shea that Sellars' problem of other minds is not the problem which, for instance, Krueger as well as Froese and Fuchs regard as the common starting point of theory theories and simulation theories. Sellars does not ask what psychological mechanism enable a subject to proceed from observations of mere behaviour, understood as bodily movements not yet perceived as expressive of any mental life, to attributions of mental states to others. Sellars' question differs in two fundamental ways from this way of posing the problem of other minds. First of all, the observed behaviour, which according to Sellars' provides the evidential basis for our theory of mind, is not restricted to meaningless movement. Secondly, Sellars' question is precisely an epistemological question about the evidential basis for our attributions of occurrent mental episodes and states to others. Sellars's question is: how can we be justified in attributing occurrent mental episodes to one another? As such, Sellars' starting point is an apparent tension between, on the one hand, what he takes to be our common sense and everyday conception of one another and, on the other hand, a certain philosophical interpretation of what can possibly give content to our common sense psychology. We do seem to attribute mental states understood as inner, occurrent episodes to both ourselves and others, and we think of these episodes as something over and above the behaviour in which such episodes can be expressed. Furthermore, we seem to think of such behaviour-transcending episodes as more than mere dispositions to behave, i.e. the other person can be undergoing an actual experience even if it is not at present expressed in her behaviour. However, given certain philosophical arguments inspired by Ryle and Wittgenstein the idea of such inner, private episodes have become intellectually suspect. All our ascriptions of mental 
states must be based on public, manifest behaviour, if we are not to reintroduce the 'ghost in the machine'. What Sellars claims to offer with his justificatory theory theory is a way of accepting the challenge from Ryle and Wittgenstein that at the same time allows us to hold on to our common sense realist picture of occurrent mental episodes. What justifies the ascription of mental episodes is their causalexplanatory role and as such the episodes are non-observable, theoretical entities, but, as O'Shea emphasizes, for Sellars this theoretical nature does not, on its own, subtract from the reality of such entities. In addition, and this is one of O'Shea's main points, the theoretical nature does not rule out that one's knowledge can be non-inferentially acquired on the basis of perception. However, if challenged such psychologically non-inferential knowledge, is ultimately to be justified by appealing to how the attribution of mental states helps explain the behaviour of the person in question rather than by reference to ones immediate perceptual experience.

As O'Shea notices, Sellars' account can be seen as raising a challenge to Stout's version of the epistemic direct perception thesis. Sellars' account apparently allows for epistemically direct perception of mental dispositions through their manifestation in behaviour, but from O'Shea's Sellarsian perspective it can looks like Stout's picture leaves such dispositions hanging mysteriously in the air. To carry this discussion further, one would need to dig into the different conceptions of causal explanations in play in O'Shea's Sellarsian approach and Stout's Ryle-inspired neo-behaviourism (see Stout 2006 for a more detailed account).

While O'Shea explicitly argues that Sellars' justificatory theory theory is neutral with regard to possible sub-personal explanations of social cognition, Froese and Fuchs' paper, 'The extended body: a case study in the neurophenomenology of social interaction', is exactly an attempt to develop an alternative to both theory theories and simulation theories understood as theories about psychological mechanisms underlying social cognition. Froese and Fuchs take it as a phenomenological datum that we sometimes directly perceive other peoples mental states. Like Stout, they also favour an enactive approach to perception as the more specific theory of perception that best accounts for the possibility of such direct perception. Their paper, however, is not so much focused on observational judgements about other minds as on a more basic level of bodily, social interaction. In the first part of the paper, they present a phenomenological description of what they term the extended body. The extended body is experienced in face-to-face encounters where we interact with others in a communicative way. The phenomenon is nicely illustrated by one of Stout's examples:

Is your friend still grieving for their dead mother? You ask them a question about their mother; they have a catch in their voice; they give you a look; you give them a hug; they weep; you console them; they continue to weep; you suggest gently that it might be time to move on; they respond aggressively that you don't know what you're talking about. You can see that they are still grieving; you can feel it. It is there, apparent in the way they are responding to you. You can feel its shape, its edges. And you do this by being part of a two person interactive emotional process. (Stout 2012)

What Fuchs and Froese refer to as 'the extended body' is the body extended through a process of interaction with another embodied being and it is normally 
experienced pre-reflectively in situations where two persons are attending to and instantly responding to one another. The two bodies so to speak extend into one another in what Fuchs and Froese, using Maurice Merleau-Ponty's term, calls an 'intertwinement' (l'interlacs). In the second part of the paper, Fuchs and Froese present a computer model of a specific instance of the extended body, namely the phenomenon of sensitivity to social contingencies observed in 2-month-old infants in Murray and Trevarthen's (1985) classic 'double TV monitor' experiment. On the basis of data analysis, Fuchs and Froese conclude that the solution generated by the computer model involving two simulated agents coordinating a common direction of movement constitute a formalization of their phenomenological notion of an extended body. Fuchs and Froese's deciding criteria for whether the model qualifies as a model of the extended body is whether the behaviour of the modelled agents generates an interaction process which itself feeds back into and regulates the internal conditions of the behaviour of the agents. On the basis of their analysis, they argue that it is possible and even plausible that the real phenomenon of sensitivity to social contingencies should be explained in a dynamic systems theoretical framework that allows for behaviour that is partly generated by properties that irreducible belong to a system encompassing both agents. Fuchs and Froese present their mathematical model of the extended body as the basis for an alternative framework for research in social cognition. Whether this approach can be applied to higher forms of cognition and eventually replace the approaches of theory theory and the simulation theory or whether what we need is a hybrid account are questions for future research.

The essays in this special issue focus on different dimensions of the problem of what is involved in the perceptual apprehension of other subjects as 'minded' beings. The problem of empathy includes many further problems which will no doubt be the focus of future studies. What we hope the papers published here illustrate is how the discussion of the direct perception approach opens up crucial questions about what we should regard as the most basic explanantia in social cognition research as well as fundamental methodological questions about the relation between phenomenological and epistemological theories on the one hand and empirical theories about psychological processes on the other hand.

Acknowledgments The editors wish to thank the Irish Research Council for the Humanities and Social Sciences (IRCHSS) who sponsored the workshop on 'Intersubjectivity and Empathy' held at the Royal Irish Academy in Dublin on May 5-6 2010. The workshop was part of the IRCHSS-funded research project 'The Phenomenology of Consciousness and Subjectivity' (PI: Dermot Moran; Assistant Investigator: Rasmus Thybo Jensen), and included earlier versions of the papers by Joel Krueger, Rowland Stout and James O'Shea. Rasmus Thybo Jensen also acknowledges the support of The Danish Council for Independent Research, Humanities.

\section{References}

Anscombe, E. (1957). Intention. Oxford: Basil Blackwell.

Austin, J. L. (1946). Other minds. Proceedings of the Aristotelian Society, Supplementary Volume 20, 148187.

Baron-Cohen, S., \& Wheelwright, S. (2004). The Empathy Quotient (EQ). An investigation of adults with Asperger syndrome or high functioning autism, and normal sex differences. Journal of Autism and Developmental Disorders, 34, 163-175.

Clark, A., \& Chalmers, D. (1998). The extended mind. Analysis, 58(1), 7-19.

Dennett, D. C. (1978). Brainstorms. Cambridge: Bradford Books. 
Dennett, D. C. (1987). The intentional stance. Cambridge: MIT Press.

Gallagher, S. (2005). Phenomenological contributions to a theory of social cognition. Husserl Studies, 21, 95-110.

Gallagher, S. (2006). Logical and phenomenological arguments against simulation theory. In D. D. Hutto \& M. Ratcliffe (Eds.), Folk psychology re-assessed (pp. 63-78). Dordrecht: Springer Publishers.

Gallagher, S., \& Zahavi, D. (2008). The phenomenological mind - an introduction to philosophy of mind and cognitive science. London and New York: Routledge.

Goldman, A. I. (1992). In defence of the simulation theory. Mind and Language, 7(1-2), 104-119.

Goldman, A. I. (2008). Mirroring, mindreading, and simulation. In J. Pineda (Ed.), Mirror neuron systems: the role of mirroring processes in social cognition. New York: Springer/Humana Press.

Goldman, A. I. (2009). Mirroring, simulating, and mindreading. Mind \& Language, 24(2), $235-52$.

Goldman, A. I., \& Shanton, K. (2010). Simulation theory. Wiley Interdisciplinary Reviews: Cognitive Science, 1, 527-538.

Gordon, R. M. (1986). Folk psychology as simulation. Mind and Language, 1, 158-171.

Heal, J. (1986). Replication and functionalism. In J. Butterfield (Ed.), Language, mind, and logic. Cambridge: Cambridge University Press. Reprinted in M. Davies and T. Stone (Eds.), Folk psychology: The theory of mind debate. Oxford: Blackwell Publishers (1995).

Heal, J. (1994). Simulation vs. theory-theory: what is at issue? In C. Peacocke (Ed.), Objectivity, simulation, and the unity of consciousness. Oxford: Oxford University Press.

Hume, D. (1978). A treatise of human nature. Oxford: Clarendon Press. Reprinted from the original edition in three volumes and edited, with an analytical index, by L.A. Selby-Bigge. 2nd edn., rev. by P. H. Nidditch.

Lipps, T. (1905). Weiteres zur 'Einfühlung'. Archiv für die gesamte Psychologie, 4(4), 465-519. Leipzig: Wilhelm Engelmann.

McDowell, J. (1998a). Criteria, defeasibility, and knowledge. In: meaning, knowledge, and reality. Cambridge: Harvard University Press.

McDowell, J. (1998b). On 'The reality of the past'. In: meaning, knowledge, and reality. Cambridge: Harvard University Press.

Moran, D. (2004). The problem of empathy: Lipps, Scheler, Husserl and Stein. In T. A. Kelly \& P. W. Rosemann (Eds.), Amor amicitiae: on the love that is friendship. Essays in medieval thought and beyond in honor of the Rev. Professor James McEvoy (pp. 269-312). Leuven: Peeters.

Murray, L., \& Trevarthen, C. (1985). Emotional regulations of interactions between two-month-olds and their mothers. In T. M. Field \& N. A. Fox (Eds.), Social perception in infants (pp. 177-197). Norwood: Alex.

Premack, D. G., \& Woodruff, G. (1978). Does the chimpanzee have a theory of mind? Behavioral and Brain Sciences, 1, 515-526.

Scheler, M. (1973). Wesen und Formen der Sympathie. Gesammelte Werke Band 7. Bern/München: Francke Verlag; The Nature of Sympathy. Trans. P. Heath. London: Routledge \& Kegan Paul, 1954.

Smith, Adam. (2002). In K. Haakonssen (Ed.), The theory of moral sentiments. New York: Cambridge University Press.

Smith, J. (2010). Seeing other people. Philosophy and Phenomenological Research, 81(3), 731-748.

Sperber, D. (Ed.). (2000). Metarepresentations. A multidisciplinary perspective. Oxford: OUP.

Stout, R. (2006). The inner life of a rational agent: in defence of philosophical behaviourism. Edinburgh: University of Edinburgh Press.

Stout, R. (2012). What someone's behaviour must be like if we are to be aware of their emotions in it. Phenomenology and the Cognitive Sciences, 11(2), 1-14. doi:10.1007/s11097-011-9224-0

Strawson, P. F. (1999). Individuals. An essay in descriptive metaphysics. Routledge: London and New York.

Stueber, K. (2006). Rediscovering empathy: agency, folk psychology, and the human sciences. Cambridge: MIT Press.

Whiten, A. (Ed.). (1991). Natural theories of mind: evolution, development and simulation of everyday mindreading. Oxford: Basil Blackwell.

Wittgenstein, L. (1980). Remarks on the philosophy of psychology II. Oxford: Blackwell.

Zahavi, D. (2010). Empathy, embodiment and interpersonal understanding: from Lipps to Schutz. Inquiry, 53(3), 285-306.

Zahavi, D. (2011). Empathy and direct social perception: a phenomenological proposal. Review of Philosophy and Psychology, 2(3), 541-558.

Zahavi, D. (2012). Empathy and mirroring: Husserl and Gallese. In R. Breeur \& U. Melle (Eds.), Life, subjectivity \& art: essays in honor of Rudolf Bernet (pp. 217-254). Dordrecht: Springer.

Zahavi, D., \& Overgaard, S. (2012). Empathy without isomorphism: a phenomenological account. In J. Decety (Ed.), Empathy: from bench to bedside (pp. 3-20). Cambridge: The MIT Press. 